\title{
Scanlon and the claims of the many versus the one
}

\section{Michael Otsuka}

John Taurek (1977) has famously argued that, when faced with the choice between saving one stranger's life and two (or more) different strangers' lives, we should follow a principle that directs us to flip a fair coin to determine whom to save just as we would do so when faced with a choice between saving one stranger and a single other stranger. We should flip a fair coin because we treat each of the one and the many with equal concern and respect only if we give each an equal and positive chance of being saved. We give the one no chance of being saved if we instead follow a principle of saving the greater number in such cases. 
In What We Owe to Each Other ${ }^{1}$ T. M. Scanlon considers and rejects Taurek's principle. According to Scanlon, it 'would be reasonable to reject a principle for deciding what to do in these cases [of one versus two] that did not give positive [and equal] weight to each person's life' (233). He maintains that Taurek's principle should be rejected on these grounds and that we should instead adopt a principle that directs us to save the greater number in cases of one versus two. Drawing heavily on an argument of Frances Kamm's (1993: 101, 114-19), ${ }^{2}$ Scanlon argues that

either member of the larger group might complain that [Taurek's] principle did not take account of the value of saving his life, since it permits the agent to decide what to do in the very same way that it would have permitted had he not been present at all, and there was only one person in each group.... This is unacceptable, the person might argue, since his life should be given the same moral significance as anyone else's in this situation. ...

Any nonrejectable principle must direct an agent to recognize a positive reason for saving each person. Since a second reason of this kind can balance the first - turning a situation in which one must save one [life when it's the only life at stake] into one in which it is permissible to save either of two people [when two lives are at stake and one cannot save both] - the reason presented by the needs of a second person in one of these two groups must at least have the power to break this tie [and justify a duty to save the two rather than the one]. (232)

One breaks the tie, according to Scanlon, by adding the claim of the second person in the group of two to that of the other person in this group. ${ }^{3}$

${ }^{1}$ Scanlon 1998: 229-41. All references will be to this work unless otherwise indicated.

2 See also Kamm 2000, where she offers the following summary of her argument:

[T] he Balancing Argument claims that in a conflict, justice demands that each person on one side should have her interests balanced against those of one person on the opposing side; those that are not balanced out in the larger group help determine that the larger group should be saved. If we instead toss a coin between one person and any number on the other side, giving each person an equal chance, we would behave no differently than if it were a contest between one and one. If the presence of each additional person would make no difference, this seems to deny the equal significance of each person. (221)

3 Scanlon maintains that 'there are grounds for thinking' of the case in question as one in which the 'moral significance [of the claim of the second person in the group of two] takes the form of a reason that is "added to" the force of other reasons [i.e., the claim of the other person in this group in this case]' (397, fn. 35). 
It is, according to Scanlon, a virtue of the above argument for saving the greater number that it does not appeal to 'reasons corresponding to the claims of groups of individuals' (231). Rather, the 'principle just defended directs an agent, under the specified conditions, to choose the course of action that yields the greater benefit, but the argument for this principle considered only objections that could be raised from the standpoints of the individuals involved' (234; cf. Kamm 1993: 101). This 'restriction to the claims of individuals' is 'one of the most appealing features' of his contractualist moral theory, which 'enables it to provide a clear alternative to utilitarianism and other forms of consequentialism' (241, 229).

In $\$ 1$ of this paper I will argue that Taurek's principle is not vulnerable to the Kamm-Scanlon objection. In $\$ 2$ I will argue that the Kamm-Scanlon argument for saving the greater number indeed depends, contrary to what Scanlon says, upon an appeal to the claim of a group of individuals to be saved.

In order to make these arguments, it will be useful to represent the Kamm-Scanlon argument a bit more formally. In the case in which we can save either one person's life or two other people's lives, let us call the one person A and the other two B and C. The Kamm-Scanlon argument for saving the greater number can be represented as follows:

(1) The claims of A, B and C should be accorded equal and positive weight. (Premiss) (232-33)

(2) We accord them equal and positive weight if and only if we add C's claim to B's. (Premiss) (232-35 and 397, fn. 35)

(3) We should add C's claim to B's. (From 1 and 2)

(4) Adding C's claim to B's tips the balance in favour of saving B and C. (Premiss) (232)

(5) This tipping of the balance in favour of saving B and C justifies saving B and C. (Premiss) (232)

(6) Saving B and $C$ is justified. (from 3, 4 and 5)

1. The premiss in step two of the argument is false: it is not true that we accord A, B and C equal and positive weight only if we add C's claim to B's. A defender of Taurek's principle can show that he gives equal and positive weight to the moral significance of each person's life by engaging in the following series of pairwise comparisons of the claims of the members of each group. ${ }^{4}$ First A's claim to be saved is compared with B's

${ }^{4}$ Cf. Nagel (1979: 122-27) and Kamm (1993: 87) for a discussion of pairwise comparison as an alternative to the aggregation of claims. Neither Nagel nor Kamm offers the argument from pairwise comparison to coin flipping that I sketch in this paragraph. 
claim. They are equally weighty. Then A's claim is compared with C's claim. Again they are equally weighty. Since things are evenly balanced in both cases, he reflects this equal balance by giving each person the same chance of being saved. He does so by flipping a coin, thereby giving each of $\mathrm{A}, \mathrm{B}$ and $\mathrm{C}$ a $50 \%$ chance of being saved. Under this method of pairwise comparison, C's claim was balanced against A's in just the same manner that B's was balanced against A's. It was given just as much weight as B's claim and just as much weight as A's claim. Admittedly a proponent of Taurek's principle would have endorsed the same result (of flipping a coin) if $\mathrm{C}$ had not been present and it had been only A versus B. But it does not follow that C's claim was given no weight, since it was given its full weight in just the same manner that each of A's and B's claims were given full weight. The weight of C's claim is reflected by the fact that he is accorded the same $50 \%$ chance of being saved as A and B.

2. I will now argue that the Kamm-Scanlon argument rests upon an appeal to the claim of a group of individuals. More precisely, it rests upon an appeal to the claim that one should save the greater number because the claim of a group of individuals to be saved outweighs the conflicting claim of a single individual to be saved. As a preliminary matter I should note that I will not argue, nor do I believe, that their argument rests upon any appeal to the consequentialist principle that one should save the greater number because it would be better if the greater number were saved, where betterness is a matter of an increase in the sum total of the good. One can appeal to the claim of a group to be saved without also invoking this consequentialist principle.

The Kamm-Scanlon argument for saving the greater number considers C's claim in combination with B's claim so that they together tip the balance in favour of saving B and C. As a means of making this point vivid, we can suppose that Kamm-Scanlon and the pairwise comparer each employ balancing scales. The pairwise comparer places $\mathrm{A}$ on the left-hand scale and $\mathrm{B}$ on the right-hand scale. Then the pairwise comparer removes $\mathrm{B}$ from the right-hand scale and places $\mathrm{C}$ on the right-hand scale (while leaving A on the left-hand scale). In both cases, the scales are evenly balanced. Kamm-Scanlon also place A on the left-hand scale and $\mathrm{B}$ on the right-hand scale, at which point the scales balance evenly. Then they tip the scales to the right by placing $\mathrm{C}$ on the right-hand scale alongside $\mathrm{B}$.

It follows from this method of tipping the balance that the KammScanlon argument appeals to 'reasons corresponding to the claims of groups of individuals'. This follows straightforwardly given the following natural interpretation of 'the claims of groups of individuals': a claim is 
that of a group of individuals when it is the claim of individuals considered together or in combination rather than one by one. I concede that the Kamm-Scanlon argument does not ever explicitly purport to advance the following claim: 'One should save B and C because their claim to be saved, when considered as the combination of B's claim and C's claim, outweighs A's claim to be saved.' If it did, then it would manifestly involve an appeal to the claim of a group of individuals to be saved. The appeal to the claim of a group in the Kamm-Scanlon argument is rendered nonmanifest by virtue of the fact that the argument seems to appeal to nothing more than C's claim to be saved, which appears by itself to justify saving the greater number. But this appearance, as I have shown above, is an illusion: $\mathrm{C}$ tips the balance in favour of saving $\mathrm{B}$ and $\mathrm{C}$ only when C's claim is combined with B's claim. The difference between the manifest appeal to the claim of a group and the unmanifest appeal is the difference between the following two claims: (a) save B and C rather than $A$ because they together tip the balance in favour of saving $B$ and $C$ and (b) save $B$ and $C$ rather than $A$ because $C$ tips the balance in favour of saving $\mathrm{B}$ and $\mathrm{C}$ when C's claim is combined with B's claim. But to assert $(\mathrm{b})$ is to assert that $\mathrm{C}$ has a claim to be saved by virtue of an appeal to the difference that $\mathrm{B}$ and $\mathrm{C}$ make when considered together or in combination rather than one by one. But this is just to appeal to the claim of a group of individuals.

Perhaps Scanlon would want to resist my interpretation of his phrase 'the claims of groups of individuals'. But whether or not my interpretation captures what he meant by this phrase, it picks out a type of interpersonal aggregation of claims that Scanlon relies upon in making his argument for the saving of the greater number. Such reliance upon this type of aggregation renders obscure his claim that 'the rightness of actions depends only on the rejectability of principles from various individual standpoints' (241). He is trying to have his cake and eat it too. ${ }^{5}$

University College London London, WC1E 6BT, UK m.otsuka@ucl.ac.uk

${ }^{5}$ I thank G. A. Cohen, Timothy Hall, and Alon Harel for their extensive commentary on previous drafts and Véronique Munoz-Dardé and the other participants in her University College London seminar for their discussion of a version of this paper which I presented there. 


\section{References}

Kamm, F. 1993. Morality, Mortality I. Oxford: Oxford University Press.

Kamm, F. 2000. Nonconsequentialism. In The Blackwell Guide to Ethical Theory, ed. H. LaFollette, 205-26. Oxford: Blackwell Publishers.

Nagel, T. 1979. Equality. In his Mortal Questions, 106-27. New York: Cambridge University Press.

Scanlon, T. 1998. What We Owe to Each Other. Cambridge, Mass.: Harvard University Press.

Taurek, J. 1977. Should the numbers count? Philosophy and Public Affairs 6: 293-316. 